\title{
OS DESAPARECIMENTOS FORÇADOS E A CLANDESTINIDADE DO REGIME MILITAR NA MESMA MARGEM DO ARAGUAIA
}

\author{
ABDUCTIONS AND THE CONCEALMENT \\ OF THE MILITARY DICTATORSHIP ON THE \\ SAME BANK OF THE ARAGUAIA RIVER
}

\author{
MENELICK DE CARVALHO NETTO ${ }^{1}$ \\ CLAUDIA PAIVA CARVALHO ${ }^{2}$ \\ GABRIEL REZENDE DE SOUZA PINTO ${ }^{3}$
}

"Não é da índole do brasileiro matar pessoas por razões políticas". Karl Loewenstein, 1942.

"Onde não existe túmulo, o trabalho de luto nunca termina". Ruth Klüger, 2005.

\begin{abstract}
RESUMO: O artigo busca retratar como a guerrilha do Araguaia alterou o padrão de repressão da ditadura militar brasileira, abandonando o legalismo e a judicialização em direção à violência radical e extrajudicial. O caso do Araguaia é emblemático porque foi alvo privilegiado da prática de crimes de desaparecimento forçado, que integraram a política de extermínio desenvolvida pelas Forças Armadas contra as forças guerrilheiras. Indica, igualmente, a clandestinidade da repressão militar, atuando paralelamente ao Estado e impondo sigilo absoluto sobre suas operações.
\end{abstract}

\footnotetext{
Artigo recebido em 15.10.2011. Pareceres emitidos em 16.12.2011, 05.01.2012 e 20.06.2012.

Artigo aceito para publicação em 13.08.2012.

${ }^{1}$ Professor Associado da Universidade de Brasília, Brasília - DF. Doutor em Direito Constitucional pela Universidade Federal de Minas Gerais, Belo Horizonte - MG. Membro do Grupo de Pesquisa Percursos, Fragmentos, Narrativas - História do Direito e do Constitucionalismo (Plataforma Lattes-CNPq).menelick@unb.br

${ }^{2}$ Mestranda em Direito, Estado e Constituição pela Universidade de Brasília, Brasília, DF. Graduada em Direito pela Universidade Federal de Minas Gerais, Belo Horizonte, MG. Membro do Grupo de Pesquisa Percursos, Fragmentos, Narrativas - História do Direito e do Constitucionalismo (Plataforma Lattes-CNPq). claudiapaivac@gmail.com

${ }_{3}$ Mestrando em Direito, Estado e Constituição pela Universidade de Brasília, Brasília, DF. Graduado em Direito pela Universidade Federal de Minas Gerais, Belo Horizonte, MG. Membro do Grupo de Pesquisa Percursos, Fragmentos, Narrativas - História do Direito e do Constitucionalismo (Plataforma Lattes-CNPq).grezendesou@gmail.com
} 
Recentemente, o julgamento do caso Gomes Lund pela Corte Interamericana de Direitos Humanos reafirmou o crime de desaparecimento forçado como violação complexa de direitos humanos, tendo determinado a tipificação do crime no ordenamento interno brasileiro. A decisão traz à tona a necessidade de se discutir não só o episódio da guerrilha, mas este período da história recente brasileira como um todo, mormente tendo em conta seus efeitos perversos que até hoje reverberam. PALAVRAS-CHAVE: Ditadura Militar; Desaparecimento Forçado; Guerrilha do Araguaia.

ABSTRACT: The present paper focus on how the Araguaia's guerrilla altered the Brazilian military dictatorship's repressive pattern, abandoning the legalized and judicialized one towards a radical and extrajudicial violence. Araguaia's case is emblematic precisely because it was a privileged target of crimes of enforced disappearance, which integrated the extermination policy developed by the Armed Forces against the combatant's forces. It also indicates the clandestine character of the military repression, acting outside of the State and imposing absolute secrecy on its operations. Recently, the Inter-American Court of Human Rights' decision in the case Gomes Lund reaffirmed the crime of enforced disappearance as a complex violation of human rights, having determined its criminalization under Brazilian domestic legal system. The decision brings to the surface the need to discuss not only the episode of the guerrilla, but this period of Brazilian's recent history as a whole, especially taking into account its perverse effects that until today reverberate.

KEYWORDS: Military Dictatorship; Enforced Disappearance; Araguaia's Conflict.

SUMÁRIO: Introdução; 1. Guerrilha do Araguaia: mudança no padrão de repressão e a desmistificação da "ditabranda"; 1.1 O Padrão de Repressão da Legalidade Autoritária Brasileira e a Violência do Regime; 1.2 Guerrilha do Araguaia e a Prática de Crimes de Desaparecimento Forçado: os "objetivos da Revolução" levados às últimas consequências; 2. O Crime de Desaparecimento Forçado no Direito Internacional; 2.1 Preliminares; 2.2 Brevíssimo Histórico da Regulação Jurídica do Crime de Desaparecimento Forçado; 3. O Caso Gomes Lund e as Implicações no Direito Interno Brasileiro; Conclusão; Referências Bibliográficas.

SUMMARY: Introduction; 1. Araguaia's Guerrilla: the demystification of "ditabranda" or changing the repressive pattern; 1.1 The Repressive Pattern of Brazilian Authoritarian Legality and the Regime's Violence; 1.2 Araguaia's Guerrilla and the Practice of Crimes of Enforced Disappearance: the "objectives of the Revolution" taken to its Last Consequences; 2. The Crime of Enforced Disappearance in International Law; 2.1 Preliminary Considerations; 2.2 A Brief History of the Crime of Enforced Disappearance's Juridical Regulation; 3. The Case Gomes Lund and the Implications in Brazilian Domestic Law; Conclusive Remarks; Bibliography.

\section{INTRODUÇÃO}

Em 1995, foi promulgada a Lei 9.140, mediante a qual o Estado brasileiro reconheceu oficialmente sua responsabilidade pelas mortes e desaparecimentos ocorridos durante o período da ditadura militar e previu a formação de uma Comissão Especial sobre Mortos e Desaparecidos Políticos, que teve como atribuições: proceder ao reconhecimento das pessoas mortas e desaparecidas, para além daquelas já relacionadas no Anexo I da Lei, envidar esforços para a localização dos restos mortais e emitir parecer acerca dos pedidos de indenização. Dos 136 nomes já constantes no Anexo da Lei 9.140/95, cerca 
de metade corresponde a combatentes mortos ou desaparecidos durante a guerrilha do Araguaia.

Este breve relato traz mais complexidade do que pode aparentar numa leitura rápida. A ideia de responsabilidade estatal, reconhecimento de desaparecidos políticos e o papel marcante da guerrilha do Araguaia dizem muito mais sobre a história da ditadura militar brasileira, sobre as dificuldades enfrentadas pela justiça de transição e os resquícios de autoritarismo presentes na realidade social, do que à primeira vista se pode supor.

O julgamento recente do caso Gomes Lund e outros vs. Brasil pela Corte Interamericana de Direitos Humanos deu um importante passo para lançar luzes sobre questões relativas ao Araguaia, aos crimes de desaparecimento forçado, à responsabilidade estatal e às medidas de não-repetição, ainda dominadas por sombras e caricaturas.

O presente trabalho busca investigar a guerrilha do Araguaia, o que ela representa e quais as suas implicações para o padrão de repressão adotado no regime militar. De forma intrinsecamente associada, analisa-se a lógica dos crimes de desaparecimento forçado dentro do governo ditatorial e da guerrilha, assumindo a perspectiva do direito internacional para melhor elucidar o significado e a configuração destes crimes. Por fim, retoma-se o caso Gomes Lund com o intuito de explorar possíveis consequências que devem repercutir no direito interno, em especial no tema de desaparecimentos forçados.

1. GUERRILHA DO ARAGUAIA: MUDANÇA NO PADRÃO DE REPRESSÃO E A DESMISTIFICAÇÃO DA "DITABRANDA"

\subsection{Padrão de Repressão da Legalidade Autoritária Brasileira e a Violência do Regime}

O regime militar brasileiro seguiu um padrão geral de repressão que se distingue dos modelos ditatoriais adotados por seus vizinhos do Cone Sul, Argentina e Chile. Tal é a hipótese defendida por Anthony W. Pereira em um estudo comparatista entre os tipos de legalidade autoritária desenvolvidos em cada um desses países em seus respectivos regimes de exceção (PEREIRA, 2010).

O caso brasileiro teria sido, segundo o autor, marcado por forte institucionalização e judicialização da repressão, seguindo uma lógica mais conservadora e gradualista no que toca o rompimento com a ordem jurídico-constitucional anterior. De fato, o Golpe de 1964 manteve em vigor a Constituição de 1946 e se anunciou como uma intervenção temporária que visava afastar a ameaça comunista que supostamente já havia contaminado o governo do presidente deposto João Goulart ${ }^{4}$, pretendendo devolver o

\footnotetext{
${ }^{4}$ Nesse sentido, o Ato Institucional de 09 de abril de 1964 arroga ao regime militar "a missão de restaurar no Brasil a ordem econômica e financeira e tomar as urgentes medidas destinadas a drenar o bolsão comunista, cuja purulência já se havia infiltrado não só na cúpula do governo como nas suas dependências administrativas" (grifos acrescidos).
} 
poder aos civis tão logo saneasse o sistema político da corrupção e subversão (PEREIRA, 2010, 119).

Mesmo combinando hibridamente uma orientação conservadora e revolucionária ${ }^{5}$, o governo militar lançou mão de instrumentos jurídicos e legais que encobriam a repressão, conferindo ao regime uma aparência de normalidade e legitimidade democrática. A Constituição de 1946 co-existiu durante três anos com a edição de atos institucionais que a neutralizavam ou afrontavam diretamente, até ceder lugar para a Carta de 1967, seguida pela Emenda Constitucional $n^{\circ} 01$ de 1969 - que era, em verdade, uma nova carta política de cariz autocrático. A edição de leis especiais, como a legislação de segurança nacional, também serviu de suporte jurídico às práticas autoritárias.

Outro ponto central à análise do autor foi o funcionamento do aparato judicial durante os anos de exceção, responsável pelos processos e julgamentos de opositores e "subversivos" pela prática de crimes políticos ou contra a segurança nacional ${ }^{6}$. A integração entre as justiças militar e civil, fruto de um consenso compartilhado entre as elites militar e judiciária acerca dos objetivos e estratégias gerais do regime, foi, segundo Pereira, decisivo para tornar possível a judicialização da repressão.

A obediência de procedimentos formais por parte da justiça política contribuiu para mascarar o arbítrio, mormente ao se ter em conta que os índices de absolvição eram relativamente altos (PEREIRA, 2010, 129), embora mantida intacta a prática sistemática de tortura durante os interrogatórios nas investigações conduzidas pelos inquéritos policial-militares. Por trás dos julgamentos de crimes políticos pairava o objetivo de se desmobilizar e deslegitimar os movimentos sociais oposicionistas, apelando para a criminalização e para a manipulação da opinião pública como forma de

\footnotetext{
${ }^{5}$ Remete-se, aqui, às categorias de ditadura comissária ou constitucional e soberana ou revolucionária trabalhadas por Carl Schmitt, sendo que a primeira tem por objetivo salvar a ordem constitucional anterior, e a segunda visa romper com a ordem antiga e propor uma nova normatividade (SCHMITT, 1968).

${ }^{6}$ É digna de nota a mudança semântica sofrida pelo conceito de segurança nacional da Constituição de 1946 para a de 1967: "Na Constituição de 1946 o conceito de Segurança Nacional era associado ao de agressão externa - defesa contra forças externas e defesa das fronteiras territoriais. A Nova Constituição mudava esta definição para adaptar-se à Doutrina de Segurança Interna, com sua teoria de guerra psicológica e do 'inimigo interno'. A ameaça à segurança nacional era assim definida como uma ameaça antes a fronteiras ideológicas do que a fronteiras territoriais. Além disso, a defesa da segurança nacional seria responsabilidade não só das Forças Armadas, como de 'toda pessoa natural ou jurídica' da sociedade civil" (ALVES, 2005, 133).

${ }^{7}$ Sobre este respeito, pondera Pereira: "Um consenso amplo, firmado entre as elites militares e judiciárias, com relação à maneira correta de organizar a repressão perdurou durante todo o regime. A expressão institucional desse consenso foi o tribunal militar, o local onde os civis acusados de transgressões da lei de segurança nacional eram processados. $O$ tribunal militar brasileiro era uma instituição híbrida, implicando em altos níveis de cooperação entre civis e militares." (PEREIRA, 2010, 142)
} 
marginalizar e retirar a credibilidade de qualquer resistência ao regime (PEREIRA, 2010, 69) ${ }^{8}$.

Observa-se com Anthony Pereira, portanto, que a utilização da lei e de tribunais serviu para reforçar o poder e a estabilidade do regime, uma vez que obscurecia a distinção entre um governo de facto e um governo de jure ou constitucional (PEREIRA, 2010, 36). Ou seja, ao manipular instrumentos jurídicos que serviam ao consumo interno e externo, o regime militar construiu um simulacro que possibilitou uma permanência no poder bem mais duradoura do que os governos ditatoriais vizinhos.

Este sistema de legalidade autoritária, tal como descrito por Pereira, influencia a abrangência e intensidade da própria repressão e repercute na abertura do regime a formas de resistência ou contestação (PEREIRA, 2010, 40). Mais especificamente, o elevado grau de judicialismo e gradualismo teriam amenizado a repressão, evitando que se radicalizasse ou assumisse um caráter predominantemente extrajudicial. Isso porque a regulamentação e judicialização das práticas repressivas impunha limites institucionais à atuação das forças de segurança, obrigadas a observar certos ditames e procedimentos, e definia um padrão de conduta em que o uso da violência não era tão massivo nem tão letal.

Exemplo disso é a realização de julgamentos dos opositores que, ao alimentar a crença no respeito - fajuto e obliterado, mas ainda assim - ao devido processo, reforçava a ideia de que era permitida a expressão de algum tipo de resistência contra o regime, a partir da própria atuação dos advogados de defesa perante os tribunais. Explica Pereira:

A repressão judicializada, mesmo em situações em que o Judiciário não é verdadeiramente independente do Executivo, tende a ser mais contida em razão das exigências de documentar sua atuação e de ter algum grau de transparência quanto aos procedimentos adotados pelo Estado. (...) Nos casos em que a repressão é judicializada, os adversários do regime tendem a ter alguns direitos a mais e um espaço um pouco maior para contestar as prerrogativas do regime. (PEREIRA, 2010, 291)

Como consequência de tais orientações e táticas, a repressão política da ditadura militar brasileira teria sido mais suave e comedida do que os regimes chileno e argentino, nos quais os níveis de violência letal foram muito superiores em função de uma política de repressão extrajudicial radical e terrorismo de Estado bem mais difundidos e profundos (PEREIRA, 2010, 56). No entanto, o problema e o risco deste diagnóstico apresentado por Pereira é o de, por meio de uma análise estatística, tingir com um caráter brando a ditadura brasileira,

\footnotetext{
${ }^{8}$ Interessante observar como, hoje, já não se admitindo considerar a oposição ao regime militar como criminosa, são frequentes as narrativas que tratam a repressão no sentido de uma guerra entre os militares e agentes da ditadura, de um lado, e os movimentos de esquerda e "terroristas" do outro. Obscurece-se, com isso, a distinção entre resistência a um regime autoritário e uma disputa entre forças equiparáveis.
} 
como se os números fossem representantes fidedignos da violência do regime. Esquece-se que uma das maiores mostras de violência da ditadura militar brasileira consiste no legado autoritário que persiste até hoje arraigado nas práticas institucionais. Há que se cuidar, portanto, para que uma comparação estatística não se transforme em um juízo de valor sobre a intensidade da repressão.

A proposta do presente trabalho é demonstrar como o episódio da guerrilha do Araguaia rompeu com a tradição legalista e conservadora do regime militar, passando a empregar a força de maneira radical e clandestina. Embora tenha havido uma radicalização da repressão nesse período conhecido como os "anos de chumbo" e designado por Elio Gaspari como "ditadura escancarada" (GASPARI, 2002), a intenção aqui é mostrar que o aprofundamento da violência, tendo no caso do Araguaia seu marco culminante, não significa um "ponto fora da curva" nem uma ocorrência excepcional dentro de um regime considerado como brando.

Ao contrário, é plausível considerar que o recrudescimento da repressão tem um sentido lógico e integra um projeto maior do regime que visava, fundamentalmente, eliminar quaisquer expressões de ideologias consideradas radicais. Se a tônica do processo repressivo a partir de 1964 foi, de modo geral, a institucionalização de um modelo de Estado centralizado que, sob o pretexto de garantir a estabilidade e afastar as crises intermitentes ${ }^{9}$, extirparia todo "radicalismo" político e social, a exacerbação da violência se prestou exatamente ao mesmo propósito, encaixando-se neste projeto.

É nesse sentido a tese proposta por Renato Lemos, que afirma que o regime militar brasileiro seguiu um paradigma "contrarrevolucionário", guiado pelo objetivo de prevenção geral, visando afastar as ameaças do comunismo, do populismo, dos movimentos de massa, etc, em prol de um projeto democrático-modernizante-conservador controlado por um Executivo forte e dirigido por uma elite tecno-empresarial (LEMOS, 2010, 14). A se adotar tal perspectiva, a distinção entre um período moderado e outro de violência brutal faz sentido enquanto mudança no padrão de repressão, mas não enquanto descontinuidade ou mudança de percurso, já que ambos estariam voltados à consecução de um mesmo projeto.

Desta forma, é indefensável a afirmação de que predominou no Brasil uma ditabranda, seja pela violência explícita ou seja pela violência oculta nas leis e instituições, que cuidava (ou cuida?) de minar a possibilidade de visões alternativas sobre os sistemas político, econômico, social. A guerrilha do Araguaia, bem como as demais medidas com maior teor de violência,

\footnotetext{
${ }^{9}$ Neste sentido, destaca-se, na exposição de motivos à Constituição de 1967, elaborada pelo então Ministro da Justiça Carlos Medeiros, o seguinte trecho: "As Constituições de 1934 e de 1946 não deram ao País a estabilidade Política; as crises que haviam começado a eclodir desde o fim da Primeira Guerra Mundial provocaram a primeira emenda, em 1926, do texto republicano de 1891. E as tréguas se estreitaram no tempo, de forma que a Nação tem vivido inquieta, desde então, sob as ameaças de ideologias radicais, tôdas divorciadas do ideal democrático e representativo" (grifos acrescidos).
} 
"rigorosamente, não modificou as características essenciais do regime, apenas as acentuou" (LEMOS, 2010, 14).

Tendo em vista essa contextualização, a guerrilha do Araguaia representa, de um lado, o coroamento da fase de repressão radical e clandestinidade do regime, e de outro, a realização do objetivo de eliminação de ideologias radicais. $O$ instrumento por excelência no combate à guerrilha foi a prática de desaparecimentos forçados, conjugando política de extermínio e sigilo absoluto. Além de desmistificar a ideia de uma ditabranda, que ainda hoje ronda os setores mais conservadores da sociedade e política brasileira, o episódio do Araguaia desvela os reais objetivos por trás do padrão de repressão legalista e conservador, levados às últimas consequências com a escalada repressiva que não se apresenta, portanto, como divisor de águas, mas como a investida mais profunda no projeto revolucionário.

Passa-se, agora, a analisar o significado da guerrilha do Araguaia e em especial do rastro de desaparecidos políticos que ela deixou.

\subsection{Guerrilha do Araguaia e a Prática de Crimes de Desaparecimento} Forçado: os "objetivos da Revolução" levados às últimas consequências

Desde 1966, militantes do Partido Comunista do Brasil (PC do B) firmaram-se na região sul do Pará, nas matas fechadas da região do Bico do Papagaio, por onde passa o rio Araguaia. Instalaram-se de forma dispersa e fragmentada nas comunidades locais, constituídas essencialmente por lavradores e camponeses, e se inseriram nos ofícios e hábitos ali praticados, exercendo atividades importantes do ponto de vista comunitário, como medicina e magistério (FORÇAS GUERRILHEIRAS DO ARAGUAIA, 1979, 26). Eram chamados "paulistas" pela população de algumas localidades.

O grupo pretendia organizar uma guerra popular prolongada no combate ao regime e na efetivação do projeto comunista, que buscava na "violência das massas" sua energia vital (GASPARI, 2002, 407). Ao fixar-se no Araguaia, o PC do B seguia uma linha política defendida desde antes do Golpe, a luta armada, e atendia a uma necessidade prática de seus membros perseguidos pela polícia, que ficavam protegidos pela floresta. A operação que preparavam era sigilosa, sendo a poucos dado conhecer a "tarefa especial" para a qual eram designados os militantes que seguiam para a "área prioritária" (GASPARI, 2002, 409). O projeto guerrilheiro planejava partir das áreas rurais para a conquista dos centros urbanos, realizando o chamado "cerco das cidades pelo campo" e construindo um exército popular de libertação, seguindo o exemplo da Revolução Chinesa (COMISSÃO ESPECIAL SOBRE MORTOS E DESAPARECIDOS POLÍTICOS, 2007, 196).

Apenas no início de 1972 o governo militar descobriu o projeto guerrilheiro do $\mathrm{PC}$ do $\mathrm{B} .{ }^{10} \mathrm{O}$ combate à guerrilha do Araguaia se estenderia até 1975 ,

\footnotetext{
${ }^{10}$ Apontam-se duas principais fontes por meio das quais as forças de segurança tomaram conhecimento da guerrilha que vinha sendo organizada pelo PC do B na região do Araguaia.
} 
sendo conformado por três campanhas militares: Operação Papagaio de 1972, Operação Sucuri no final do mesmo ano e a Operação Marajoara a partir de outubro de 1973.

A guerrilha organizou-se em três destacamentos ( $A, B$ e $C$ ), cada um com vinte combatentes e dois chefes, além de uma comissão militar composta por quatro dirigentes. No início dos conflitos com as tropas, somavam-se cerca de 71 guerrilheiros. Ao longo de todo o confronto, as forças guerrilheiras enfrentaram as investidas das Forças Armadas com um contingente humano absolutamente menor, armamento escasso e de má qualidade e um poder de fogo muito inferior (GASPARI, 2002, 416). Ainda assim, a estrutura guerrilheira não foi facilmente desmontada pelo regime militar.

Segundo o jornalista Elio Gaspari, "ao contrário do que sucedera no enfrentamento com a esquerda armada das cidades, no Araguaia as coisas começaram diferentes. Os militares comportaram-se como uma força de ocupação" (GASPARI, 2002, 418). Importa notar rapidamente como essa "força de ocupação" se comportou em cada ofensiva militar.

Inicialmente, os guerrilheiros capturados eram levados presos e usados como fonte de informação, não perdendo a vida ou "desaparecendo". Nas primeiras incursões, os militares se organizaram em efetivos de grande número, mas as tropas eram compostas majoritariamente por recrutas que não tinham boa desenvoltura na mata, além de faltar-lhes informação sobre o terreno e o inimigo. Na relação com as populações locais, as patrulhas pregavam uma propaganda de contra-insurgência e buscavam colaboradores, oferecendo recompensa a quem capturasse algum "paulista".

No entanto, se por um lado alguns prisioneiros foram poupados, de outro, aqueles que morriam, sumiam. A nova estratégia de desaparecimento dos opositores políticos foi posta em ação:

A ditadura fixava um padrão de conduta. Fazia prisioneiros, mas não entregava cadáveres. Jamais reconheceria que existissem. Quem morria, sumia. Esse comportamento não pode ser atribuído às dificuldades logísticas da região, pois a tropa operava de acordo com uma instrução escrita: "Os PG (prisioneiros de guerra) falecidos deverão ser sepultados em cemitério escolhido e comunicado". (GASPARI, 2002, 420).

Dado o mau desempenho da primeira e segunda campanhas, a terceira ofensiva foi precedida de uma ampla operação de inteligência. Os militares se prepararam para cercar o movimento com soldados profissionais da força especial do Exército que, habituados à vida na floresta, camuflaram-se na

A primeira seria pelo guerrilheiro Pedro Albuquerque que teria fugido da mata com a mulher grávida. A segunda seria a guerrilheira Regina que se encontrava em São Paulo recebendo tratamento médico. Não obstante, Albuquerque alega que os militares já sabiam da estrutura montada pelo PC do B na floresta ao sul do Pará (GASPARI, 2002, 414). 
mata sem o uso da farda e fizeram valer a lei da selva e da barbárie, no lugar da lei da guerra. ${ }^{11} \mathrm{O}$ terror de Estado foi amplamente disseminado, e as próprias populações locais passaram a viver num ambiente de absoluto medo, no qual camponeses foram coagidos e intimidados a trabalhar para o aparelho de repressão, além de sofrerem prisões em massa e agressões patrimoniais ${ }^{12}$ (GASPARI, 2002, 439). A partir daí, fica explícita a política de eliminação dos guerrilheiros detidos.

Se os guerrilheiros eram todos uns "fanáticos", como definidos por João Baptista Figueiredo, "as tropas passaram a entrar em combate com a disposição de atirar para matar - e não a de fazer prisioneiros" (STUDART, 2006, 256). Com efeito, todos os guerrilheiros presos durante a terceira campanha foram mortos, seja sob tortura ou fuzilamento, sem respeito a qualquer direito ou princípio. Em depoimento prestado, o coronel da reserva Pedro Cabral confirma a estarrecedora política de eliminação que, segundo ele, converteu-se em uma "caçada levada a termo por verdadeiros monstros" (GASPARI, 2002, 453). Não importava que os guerrilheiros estivessem em situação de total submissão ou mesmo que se apresentassem em rendição: foram brutalmente assassinados. Diante disso, é difícil crer na suposta "relutância" das forças armadas brasileiras "a usar a força de modo rígido, unilateral e extrajudicial" (PEREIRA, 2010, 106).

Ademais, atesta o ex-coronel no mesmo depoimento que "eram ordens de Brasília (...) que não ficasse ninguém vivo" e, posteriormente, "que não se deixassem vestígios de que o conflito do Araguaia algum dia tivesse existido" (MIRANDA, 1999, 196). Sob tais ordens é que teria ocorrido, após o fim da guerrilha, a "operação limpeza", em que os restos mortais dos guerrilheiros teriam sido desenterrados e jogados ao mar ou queimados com pneus, embora esta versão seja contestada. Em todo caso, o governo militar impôs silêncio absoluto sobre os acontecimentos do Araguaia e proibiu a imprensa de dar notícias sobre o tema, enquanto o Exército negava a existência do movimento (COMISSÃO ESPECIAL SOBRE MORTOS E DESAPARECIDOS POLÍTICOS, 2007, 199).

\footnotetext{
${ }^{11}$ Nesse sentido: "Há muito que se suspeita que um grupo significativo de militares que combateu a guerrilha rural do Araguaia deixou que prevalecessem práticas de exceção e violento radicalismo no campo de batalha. Teriam matado quem poderiam prender, abandonado corpos insepultos, cortado cabeças, torturado inimigos, executado prisioneiros, teriam enfim agido como bárbaros". (STUDART, 2006, 17).

${ }^{12}$ De acordo com o livro-relatório Direito à Memória e à Verdade: "Nessa terceira fase, em algumas localidades foram presos praticamente todos os moradores homens. O Exército os enfiava em buracos fundos, cavados na terra e cobertos por grades. Lavradores suspeitos de colaborar com os guerrilheiros tiveram suas plantações destruídas ou até mesmo perderam suas terras. Os helicópteros do Exército e da FAB eram utilizados com tinta cobrindo as insígnias das Armas, de modo a esconder o caráter oficial da operação." (COMISSÃO ESPECIAL SOBRE MORTOS E DESAPARECIDOS POLÍTICOS, 2007, 199). Denuncia-se com isso que não apenas aqueles que pegaram em armas foram alvos da ação violenta do governo militar; qualquer contato ou simpatia pelos "paulistas" ensejavam tortura, prisão e maus-tratos à população local.
} 
Enquanto os propósitos de extermínio e sigilo sobre as operações no Araguaia se combinavam, a prática de crimes de desaparecimento forçado serviu a ambos. Cometidos de forma generalizada e sistemática na guerrilha, os desaparecimentos representam o marco do recrudescimento da ditadura militar, que radicalizou a violência e o terror, bem como o uso de vias clandestinas e extrajudiciais, mas sem se desviar dos objetivos da Revolução que buscavam neutralizar todas as ameaças ou focos de instabilidade política, em especial quando capiteneados por movimentos de índole comunista.

No que toca a preocupação do regime em eliminar todo e qualquer vestígio da guerrilha, "como se não tivesse acontecido", nota-se que atuam, ao mesmo tempo, o poder oculto (que se oculta) e o poder que oculta (que se esconde escondendo) (STUDART, 2006, 18). Sob pretensas razões de Estado ou de segurança nacional, o regime guardou sigilo sobre o Araguaia e, para tanto, agiu de forma furtiva e, por que não, mentirosa.

A este respeito, Hannah Arendt vai afirmar em "A mentira na política" que o sigilo - discrição ou arcana imperii (mistérios do governo) - e o embuste falsidade deliberada e mentira descarada - são utilizados com fins políticos desde os primórdios da história documentada (ARENDT, 1999, 14). Tais práticas tornam-se possíveis essencialmente em razão da vulnerabilidade textual dos fatos, que ficam sujeitos a mentiras comuns e organizadas, até falsidades cuidadosamente construídas em camadas, ou mesmo, no extremo, a armadilhas do esquecimento (ARENDT, 1999, 16). No entanto, a despeito do poder da mentira, ela é em geral derrotada pela realidade. É isso que se espera que ocorra com relação à história da guerrilha do Araguaia, em particular, e da ditadura militar como um todo. $\mathrm{O}$ instrumento para opor-se a realidade contra a mentira é o trabalho de memória, ainda que com todas as contingências e limitações a ele inerentes, a começar pelo acesso, sempre mediatizado subjetivamente, ao passado opressor. Mas este já é um outro debate. Por ora, voltemos ao Araguaia.

Uma razão apontada para a política de sigilo do regime era o forte temor de que fosse criada na região do Araguaia uma área liberada, reconhecida como região autônoma e independente do Brasil, na qual ocorria uma guerra civil (STUDART, 2006, 34). O tratamento do conflito como assunto secreto perante o público externo tinha por escopo, portanto, evitar sua propagação e um consequente ganho de importância aos olhos da Nação. ${ }^{13}$ Para Gaspari:

[A] ditadura temia que a propagação das notícias de combates, mesmo ocorrendo apenas no exterior e em canais semiclandestinos, desse notoriedade à guerrilha. Era o medo de que se transformasse numa "zona liberada" como sucedera nas guerras do gênero no Sudeste da Ásia. O general Médici queria que a campanha seguisse em silêncio: "Era preciso esconder as operações para que elas tivessem sucesso". (GASPARI, 2002, 435).

\footnotetext{
${ }^{13}$ Destaque para a repercussão que a guerrilha teve internacionalmente mediante a transmissão dos feitos da revolta camponesa pela Rádio Tirana, da Albânia.
} 
Também as forças guerrilheiras encampam este pensamento, que vem registrado no Diário da Guerrilha do Araguaia:

Face aos acontecimentos do sul do Pará nos quais estão envolvidos numerosos contingentes das Forças Armadas, a ditadura mantém completo silêncio. A censura é férrea sobre a imprensa e outros meios de comunicação. Os generais temem que a notícia da resistência heróica possa contagiar de entusiasmo as grandes massas da população. (FORÇAS GUERRILHEIRAS DO ARAGUAIA, 1979, 49).

Em consequência, "[o] segredo da operação militar determinou a clandestinização da ação do Estado. O Araguaia não produziu inquéritos policial-militares, denúncias formais ou sentenças judiciais" (GASPARI, 2002, 435). Ou seja, a judicialização já não servia de padrão à política repressiva. Ao contrário, as ideias de sigilo/clandestinidade e extermínio/radicalidade se imbricaram como pressupostos mutuamente dependentes: a prática de extermínio serviu para guardar o sigilo, e o sigilo garantiu a possibilidade do extermínio. Dentro desta lógica, "o CIE combatia a História, para que nela não existisse guerrilha" (GASPARI, 2002, 462).

Outra razão que teria imposto o silêncio sobre o extermínio e desaparecimento de militantes seria o propósito de se evitar a incongruência entre um discurso que já anunciava uma distenção e abertura do regime e a persistência de relatos oficiais sobre mortes de opositores que supostamente teriam cometido suicídio ou entrado em choque com as forças de segurança. A decisão da Corte Interamericana de Direitos Humanos no caso Gomes Lund destacou este descompasso como motivo para o sigilo absoluto acerca das operações no Araguaia, como indicado no relatório Direito à Memória e à Verdade da Comissão Especial sobre Mortos e Desaparecidos Políticos:

O desaparecimento de presos políticos, que antes era apenas uma parcela das mortes ocorridas, torna-se regra predominante para que não ficasse estampada a contradição entre discurso de abertura e a repetição sistemática das velhas notas oficiais simulando atropelamentos, tentativas de fuga e falsos suicídios. (COMISSÃO ESPECIAL SOBRE MORTOS E DESAPARECIDOS POLÍTICOS, 2007, 27)

Por fim, como já ressaltado no item anterior, o caso do Araguaia não pode ser visto como um episódio singular e isolado ao longo da ditadura militar, como se tivesse concentrado o exercício clandestino e radical da violência pelo Estado contra a orientação legalista e gradualista que teria até então predominado. Ao contrário, como atesta Elio Gaspari, "o massacre do Araguaia foi o apogeu de uma concepção política na qual se embutira 0 extermínio das militâncias esquerdistas" (GASPARI, 2002, 463). A seguir, acrescenta o autor que "o recurso ao assassinato e a ideia da eliminação das lideranças e dos principais quadros das organizações armadas era-lhe [à guerrilha] anterior" (GASPARI, 2002, 463). 
Gaspari destaca, ainda, que antes mesmo de se ter conhecimento do Araguaia, em 1971, ao menos quatorze presos políticos desapareceram e foram executados nas mesmas condições de submissão. O fato de que, no final de 1973, pela primeira vez na ditadura, o número de desaparecidos políticos se aproximou ao de mortos oficialmente reconhecidos é sintomático do comportamento assumido pelo regime militar. Em suma, "o que sucedeu no Araguaia foi amostra radical, não episódio isolado" (GASPARI, 2002, 464).

Após brutalmente exterminado o movimento do Araguaia, quando se preparava para assumir a Presidência, o general Ernesto Geisel recebeu a ditadura "sabendo que dentro dela estava montada uma máquina de extermínio das lideranças esquerdistas. Não havia mais guerrilha, muito menos terrorismo. Sobrara a máquina" (GASPARI, 2002, 464).

É certo que esta postura do regime militar não se compadecia com a continuidade de um padrão de repressão legalista e judicializado. Não é fortuito ou trivial o fato de que a maioria dos acusados por crimes políticos submetidos a julgamento não o foram por participação na ação armada, mas por crimes de opinião ou de associação (PEREIRA, 2010, 39). Os integrantes da resistência armada, como a guerrilha do Araguaia, foram eliminados de forma sumária e extrajudicial, sendo-lhes negado até o direito de ter suas mortes e as circunstâncias em que ocorreram reveladas a seus familiares ou oficialmente reconhecidas.

A prática de desaparecimentos forçados foi, portanto, decisiva à intensificação do regime em prol de uma maior radicalidade e clandestinidade do padrão de repressão, e a guerrilha do Araguaia ocupou posição central, ao ponto de metade dos desaparecidos políticos hoje reconhecidos oficialmente na Lei 9.140/05 serem dela provenientes.

$\mathrm{Na}$ verdade, o crime de desaparecimento forçado, combinando detenção arbitrária e eliminação extrajudicial com o silêncio sobre o paradeiro das vítimas, traz em si os principais componentes da repressão em sua forma mais violenta, justificada pelos mesmos objetivos da Revolução que buscavam afastar quaisquer ameaças à estabilidade política, a ser conquistada por meio do expurgo das ideologias radicais. Este crime merece, por tudo isso, uma análise mais detida a partir de sua configuração no Direito Internacional.

\section{O CRIME DE DESAPARECIMENTO FORÇADO NO DIREITO INTERNACIONAL}

\subsection{Preliminares}

O desaparecimento forçado de pessoas, antes de ser tomado em toda a complexidade de sua dimensão jurídica, precisa ser pensado como fenômeno político-social. Isso equivale a dizer que ao tratá-lo como crime - ou, caso se prefira adotar o jargão das ciências criminais, fato típico - não se pode descurar de seu aspecto mais profundo: o desaparecimento forçado é um modo de o poder político estabelecido lidar com sua oposição. 
Neste sentido, e não em outro, seria possível dizer que o desaparecimento forçado de pessoas é tão antigo quanto a própria política.

As formas de eliminação dos opositores, dos dissidentes e dos divergentes recebem, contudo, contornos dramáticos a partir do séc. XX. Afinal, as grandes tragédias do período são marcadas não apenas por uma perseguição obstinada contra todos eles, mas por algo que se poderia chamar de fantasmagorização. O neologismo precário aspira sublinhar a extensão da própria ideia de fazer alguém desaparecer. O resultado de uma ausência causada não se exaure na simples retirada de determinado sujeito da vida política. Ele é, antes, exatamente a produção desta ausência, o tornarpresente um ausente. De suma importância se revela a distinção proposta por Jacques Derrida entre o espectro e o fantasma: em se tratando de desaparecidos, a intenção própria dos regimes autocráticos é a produção de fantasmas, mortos-vivos presentes através de ilusões, de simulacros (REGAZZONI, 2008). Ao contrário do fantasma todo-poderoso da soberania (DERRIDA, 2001), o desaparecido é um fantasma débil, fraco, destituído, despossuído: reside aí seu efeito devastador. Sem que dele se possa ter qualquer notícia, tanto sua morte quanto sua vida permanecem em suspenso, restando nada mais que uma ilusão social. O desaparecimento forçado, no séc. XX, caracteriza-se não por um apagamento de rastros, mas por um conjunto de negativas dos poderes públicos implicados que, ao fazê-lo, traçam rastros que já não mais podem ser retraçados.

Ainda que existam discussões sobre seu marco inicial, não há dúvidas que uma de suas experiências princeps é justamente o Nacht und Nebel. A partir de um decreto de 12 de dezembro de 1941, o Terceiro Reich começaria a empregar medidas que se voltariam contra a população civil. O objetivo claro era uma espécie de prevenção geral, ou seja, impedir atividades - entendidas como delituosas - que se opusessem de qualquer forma ao regime. É fundamental, neste particular, o depoimento prestado por Wilhelm Keitel perante o Tribunal Militar Internacional de Nuremberg. Keitel resumirá a política nazista ao dizer que

o Führer acredita que, no caso de tais crimes, prisão perpétua - mesmo prisão perpétua com trabalhos forçados - seria sinal de fraqueza. Uma efetiva e duradoura prevenção geral pode ser alcançada somente com a pena de morte ou com a tomada de medidas que deixem a família e a população incertas sobre o destino do criminoso. A deportação para a Alemanha serve a este propósito ${ }^{14}$ (INTERNATIONAL MILITARY TRIBUNAL, 1950, p. 24, tradução nossa).

\footnotetext{
${ }^{14}$ No texto consultado: "The Führer thinks that in the case of such offences life imprisonment, even life imprisonment with hard labour, is regarded as a sign of weakness. An effective and lasting deterrent can be achieved only by the death penalty or by taking measures which will leave the family and the population uncertain of the fate of the offender. The deportation to Germany serves this purpose".
} 
Fica claro que o fim perseguido vai além da eliminação de um único adversário político, albergando muito mais um plano concertado de dissuasão coletiva. Ao mesmo tempo em que se nega o paradeiro e a existência do desaparecido, seu fantasma é conjurado à cena pública para infligir medo e terror à família e à população civil. O caráter complexo do crime de desaparecimento nasce da própria função que ele desempenha nas autocracias do séc. XX.

Não por outra razão CITRONI e SCOVAZZI vão enfatizar a multiplicidade de bens jurídicos violados por esta prática delitiva. Segundo os autores, podem estar implicados a um só tempo violações ao direito de não ser privado arbitrariamente de sua liberdade; ao direito de proteção sob o Estado de Direito; ao direito à dignidade; ao direito de não receber tratamento desumano, cruel ou tortura; ao direito à vida; ao direito à família; ao direito de liberdade de expressão e liberdade de expressão religiosa; e à proibição geral de discriminação arbitrária (2007). A Corte Interamericana de Direitos Humanos (CIDH) também afirmou em diversas oportunidades o caráter múltiplo da desaparição forçada: em Goiború e outros vs. Paraguai, por exemplo, afirma-se o quão insidioso é este aspecto.

Sustenta-se aqui, portanto, o duplo caráter do crime em comento: a fantasmagorização do desaparecido e a multiplicidade dos bens jurídicos violados. A partir de uma tal equação poderá ser observado o desenvolvimento das regras de direito internacional em relação à matéria e seu enquadramento entre os crimes contra a humanidade.

\subsection{Brevíssimo Histórico da Regulação Jurídica do Crime de Desaparecimento Forçado}

Para além das dificuldades que serão tratadas a seguir, é importante salientar que o crime de desaparecimento forçado possui seu desenvolvimento internacional bastante ligado aos instrumentos de proteção dos direitos humanos latino-americanos. A despeito de todo um trabalho da Comissão Interamericana de Direitos Humanos (Comissão IDH), que lhe são anteriores, é apenas na década de noventa que serão observados os primeiros tratados visando especificamente a matéria.

A Declaração Internacional sobre o direito das pessoas contra os desaparecimentos forçados, datada de 1992, aparece como um primeiro esforço para adoção de princípios comuns, no interior mesmo da Assembléia Geral das Nações Unidas. Por seu caráter de declaração, contudo, seus efeitos jurídicos são bastante limitados, não aportando muito mais do que princípios diretivos.

É no quadro da Organização dos Estados Americanos (OEA) que se verá firmado o primeiro acordo internacional com teor obrigatório específico sobre a matéria. Em seu Art. $4^{\circ}$, a Convenção Interamericana sobre o Desaparecimento Forçado de pessoas insere a conduta delitiva entre os crimes de lesa-humanidade sob a seguinte conceituação: 
Artigo $2^{\circ}$. Para os efeitos desta Convenção, entende-se por desaparecimento forçado a privação de liberdade de uma ou mais pessoas, seja de que forma for, praticada por agentes do Estado ou por pessoas ou grupos de pessoas que atuem com autorização, apoio ou consentimento do Estado, seguida de falta de informação ou da recusa a reconhecer a privação de liberdade ou a informar sobre o paradeiro da pessoa, impedindo assim o exercício dos recursos legais e das garantias processuais pertinentes. (ORGANIZAÇÃO DOS ESTADOS AMERICANOS, 1994)

No sistema universal, as regras obrigatórias serão adotadas num duplo movimento. Em primeiro lugar, depois de vivas controvérsias nos trabalhos preparatórios, inclui-se o desaparecimento forçado entre os crimes contra a humanidade de competência do Tribunal Penal Internacional. Trata-se de importante virada, pois nenhum outro documento de caráter universal havia feito essa relação anteriormente (CITRONI; SCOVAZZI, 2007, p. 256). Por outro lado, um tratado específico será acordado em 2006, intitulado Convenção Internacional para a Proteção de Todas as Pessoas contra o Desaparecimento Forçado.

A despeito desta evolução normativa baseada na produção de tratados internacionais sobre a matéria, há que se notar um dissenso na literatura sobre a formação de uma regra convencional de direito internacional e os efeitos disto para sua determinação enquanto norma de jus cogens. Antonio Cassese entende que, neste particular, o Estatuto de Roma do Tribunal Penal Internacional não codificou uma regra existente de direito costumeiro, tendo antes contribuído para a cristalização de uma norma nascente (CASSESE, $2008,113)$. Donde se retiram diversas consequências importantes, sobretudo no que toca o respeito aos princípios da legalidade e da anterioridade da lei penal.

Por outro lado, Brian Finucane (2010) vai sustentar a hipótese de que, ao contrário da opinião clássica, representada por Cassese, o crime de desaparecimento forçado se desenvolve não a partir da legislação de direito internacional dos direitos humanos, mas do ordenamento de direito humanitário internacional. De sorte que, a partir deste ponto de vista, o desaparecimento forçado seria originalmente um crime de guerra, já sendo declarado como tal nos julgamentos de Nuremberg. $\mathrm{O}$ argumento de Finucane é bastante convincente. Apoiando-se em todo um conjunto de proibições relacionadas ao ius in bello que se estabelece desde fins do séc XIX, culminando no Art. $3^{\circ}$ comum às quatro Convenções de Genebra de 1949, Finucane observa a vedação à desaparição forçada como criminalização de uma conduta que ofende o direito de respeito à família. É sua a melhor síntese:

As evidências desta seção ilustram três fatos-chave. Primeiro, a conduta criminal tipificada no crime de desaparecimento forçado vem sendo proibida pelo Direito Humanitário Internacional desde o séc XIX. Segundo, a 
proibição é baseada na proteção da família. Terceiro, violações desta proibição acarretam responsabilidade criminal (FINUCANE, 2010, p. 187, tradução nossa) ${ }^{15}$.

Portanto, o caminho deste desenvolvimento, que se inicia no Direito Humanitário Internacional, desde o séc. XIX, importa na translação da conduta ao domínio dos crimes contra a humanidade no corpus jurídico de proteção dos direitos humanos. A partir do que se pode afirmar a coerência do entendimento da CIDH no caso Vélasques Rodríguez vs. Honduras quando defende que

ainda que não exista nenhum texto convencional em vigência, aplicável aos Estados-parte da Convenção, que empregue esta qualificação, a doutrina e a prática internacional muitas vezes o qualificam como crime contra a humanidade (CIDH, 1988, p. 31, para. 153, tradução nossa $)^{16}$.

\section{O CASO GOMES LUND E AS IMPLICAÇÕES NO DIREITO INTERNO BRASILEIRO}

Observou-se até o momento uma evolução na afirmação do desaparecimento forçado enquanto crime contra a humanidade. Seu aspecto naturalmente fantasmagórico - no sentido derrideano - e complexo implica um amplo espectro de bens jurídicos violados, os quais gravitam em torno da pessoa do desaparecido e de sua família.

Por consistir numa privação de liberdade - e da vida, como na maioria dos casos -, seguida da negação de informações sobre o paradeiro ou destino do desaparecido, o sujeito ativo da conduta necessariamente será um agente Estatal ou membro de uma organização política - introdução esta feita, no plano internacional, pelo Estatuto de Roma [Art. 7(2)(i)]. Reside aí a transformação do desaparecido em fantasma: desaparece da cena pública, mas nela permanece enquanto negação. Todos sabem quem ele é, e por quem fora privado de sua liberdade, não existindo, contudo, espaço próprio para que se possa negar a negação. O elemento subjetivo do tipo (mens rea) ${ }^{17}$ também aponta para esta fantasmagoria, uma vez que o agente deverá portar a intenção de remover a vítima da proteção da lei por um período de tempo prolongado (WERLE, 2005, 259-261).

\footnotetext{
${ }^{15}$ No original: "The evidence in this Part illustrates three key facts. First, the conduct underlying enforced disappearance has been prohibited by IHL since the nineteenth century. Second, the prohibition is rooted in the protection of the family and familial integrity. Third, violations of this prohibition carry individual criminal liability".

${ }^{16} \mathrm{Na}$ versão espanhola da sentença: "Si bien no existe ningún texto convencional en vigencia, aplicable a los Estados Partes en la Convención, que emplee esta calificación, la doctrina y la práctica internacionales han calificado muchas veces las desapariciones como un delito contra la humanidad".

${ }^{17}$ Não resta dúvida de que esta terminologia é bastante imprópria. Contudo, dada a tradição do direito brasileiro de pensar o direito penal sob a chave da tipicidade, adotou-se aqui o termo elemento subjetivo do tipo. Entretanto, em Direito Internacional Penal, não há que se falar de prevalência do Tatbestand.
} 
Pela própria característica da conduta delitiva, não é difícil ver por que ela foi o modo primordial de tratamento dispensado à oposição nas autocracias do continente latino-americano. Seus efeitos sob o tecido social são dramáticos, produzindo um sentimento difundido de insegurança fundado na mais absoluta certeza de que se vive sob a égide de um Estado criminoso. As decisões deste último e de seus agentes não estão sujeitas a qualquer tipo de controle e ocorrem em total descompasso com o Estado de Direito. Mesmo o conjunto de atos que supostamente possam afrontar politicamente o regime não estão claros, ainda que se possa prever o desaparecimento como o destino certo daqueles que porventura representem uma qualquer ameaça.

Essas nuances estão, ainda que indiretamente, contempladas na decisão da CIDH no caso Gomes Lund e outros vs. Brasil. Em sentença do dia 24 de novembro de 2010, os juízes se depararam mais uma vez com uma acusação de desaparecimento forçado. O tom dos votos deixa entrever que há uma firme jurisprudência construída ao longo dos anos, a qual a Corte apenas reafirma. Por esta razão, os fatos trazidos ao caso, relatando o acontecido durante a guerrilha do Araguaia e as subsequentes medidas empregadas para ocultar os cadáveres, foram facilmente subsumidos na categoria de desaparecimento forçado de pessoas. A condenação, que já era esperada mesmo antes do julgamento final da causa, revela antes de mais nada a coerência interna dos julgamentos da CIDH sobre a matéria:

110. De todo o exposto, pode-se concluir que os atos que constituem o desaparecimento forçado têm caráter permanente e que suas consequências acarretam uma pluriofensividade aos direitos das pessoas reconhecidos na Convenção Americana, enquanto não se conheça o paradeiro da vítima ou se encontrem seus restos, motivo pelo qual os Estados têm o dever correlato de investigar e, eventualmente, punir os responsáveis, conforme as obrigações decorrentes da Convenção Americana (CIDH, 2010, p. 41, para. 110).

De fato, em se pensando o direito como integridade - seguindo a proposta de Ronald Dworkin (1986) -, não havia ali outra decisão correta senão a de condenar o Brasil. Ainda que a Lei 9.140/95 e a publicação do livro Direito à Memória e à Verdade representem um marco inicial - e muito importante - de revisitação crítica dos anos de chumbo, é claro que não são suficientes, per si, para assegurar o cumprimento das normas de proteção aos direitos humanos a que o Brasil está vinculado. Nem, tampouco, são suficientes para o caso concreto em análise. O Estado brasileiro, portanto, foi considerado responsável pela violação dos direitos contidos nos Arts. $3^{18}, 4^{19}$, $5^{20}$ e $7^{21}$ da Convenção Americana de Direitos Humanos.

\footnotetext{
${ }^{18}$ Artigo $3^{\circ}$ - Direito ao reconhecimento da personalidade jurídica. Toda pessoa tem direito ao reconhecimento de sua personalidade jurídica.

${ }^{19}$ Artigo $4^{\circ}$ - Direito à vida. 1. Toda pessoa tem o direito de que se respeite sua vida. Esse direito deve ser protegido pela lei e, em geral, desde o momento da concepção. Ninguém pode ser
} 
Mas quais são as consequências desta condenação? A questão suscitará nos próximos anos enorme controvérsia. Isto porque, caso se compare os efeitos desta condenação no plano regional ao julgamento da Ação de Descumprimento de Preceito Fundamental (ADPF) 153, poderá ser observada a intensa incongruência entre os dois julgados. Na primeira, a CIDH determina expressamente que o Brasil tipifique o crime de desaparecimento forçado e - o que é importante aqui - garanta o efetivo julgamento e punição dos perpetradores de desaparecimentos forçados. Ademais, deverá dar sequência às investigações relativas à guerrilha do Araguaia, notadamente com o objetivo de encontrar os restos mortais dos desaparecidos. Como fazê-lo, contudo, se a partir ADPF 153 determinou-se o esquecimento? Como fazê-lo

privado da vida arbitrariamente. 2. Nos países que não houverem abolido a pena de morte, esta só poderá ser imposta pelos delitos mais graves, em cumprimento de sentença final de tribunal competente e em conformidade com a lei que estabeleça tal pena, promulgada antes de haver 0 delito sido cometido. Tampouco se estenderá sua aplicação a delitos aos quais não se aplique atualmente. 3. Não se pode restabelecer a pena de morte nos Estados que a hajam abolido. 4. Em nenhum caso pode a pena de morte ser aplicada a delitos políticos, nem a delitos comuns conexos com delitos políticos. 5. Não se deve impor a pena de morte a pessoa que, no momento da perpetração do delito, for menor de dezoito anos, ou maior de setenta, nem aplicá-la a mulher em estado de gravidez. 6. Toda pessoa condenada à morte tem direito a solicitar anistia, indulto ou comutação da pena, os quais podem ser concedidos em todos os casos. Não se pode executar a pena de morte enquanto o pedido estiver pendente de decisão ante a autoridade competente.

${ }^{20}$ Artigo $5^{\circ}$ - Direito à integridade pessoal 1 . Toda pessoa tem direito a que se respeite sua integridade física, psíquica e moral. 2. Ninguém deve ser submetido a torturas, nem a penas ou tratos cruéis, desumanos ou degradantes. Toda pessoa privada de liberdade deve ser tratada com o respeito devido à dignidade inerente ao ser humano. 3. A pena não pode passar da pessoa do delinquente. 4. Os processados devem ficar separados dos condenados, salvo em circunstâncias excepcionais, e devem ser submetidos a tratamento adequado à sua condição de pessoas não condenadas. 5. Os menores, quando puderem ser processados, devem ser separados dos adultos e conduzidos a tribunal especializado, com a maior rapidez possível, para seu tratamento. 6 . As penas privativas de liberdade devem ter por finalidade essencial a reforma e a readaptação social dos condenados.

${ }^{21}$ Artigo $7^{\circ}$ - Direito à liberdade pessoal 1. Toda pessoa tem direito à liberdade e à segurança pessoais. 2. Ninguém pode ser privado de sua liberdade física, salvo pelas causas e nas condições previamente fixadas pelas Constituições políticas dos Estados-partes ou pelas leis de acordo com elas promulgadas. 3 . Ninguém pode ser submetido a detenção ou encarceramento arbitrários. 4. Toda pessoa detida ou retida deve ser informada das razões da detenção e notificada, sem demora, da acusação ou das acusações formuladas contra ela. 5. Toda pessoa presa, detida ou retida deve ser conduzida, sem demora, à presença de um juiz ou outra autoridade autorizada por lei a exercer funções judiciais e tem o direito de ser julgada em prazo razoável ou de ser posta em liberdade, sem prejuízo de que prossiga o processo. Sua liberdade pode ser condicionada a garantias que assegurem o seu comparecimento em juízo. 6. Toda pessoa privada da liberdade tem direito a recorrer a um juiz ou tribunal competente, a fim de que este decida, sem demora, sobre a legalidade de sua prisão ou detenção e ordene sua soltura, se a prisão ou a detenção forem ilegais. Nos Estados-partes cujas leis prevêem que toda pessoa que se vir ameaçada de ser privada de sua liberdade tem direito a recorrer a um juiz ou tribunal competente, a fim de que este decida sobre a legalidade de tal ameaça, tal recurso não pode ser restringido nem abolido. O recurso pode ser interposto pela própria pessoa ou por outra pessoa. 7. Ninguém deve ser detido por dívidas. Este princípio não limita os mandados de autoridade judiciária competente expedidos em virtude de inadimplemento de obrigação alimentar. 
se o Supremo Tribunal Federal afirmou que a Lei de Anistia é válida e sua interpretação correta deve prevenir qualquer forma de ação penal contra crimes cometidos por agentes políticos da repressão?

Ao que tudo indica, caminha-se para mais um debate sobre quem é o soberano.

O passado que não passa.

\section{CONCLUSÃO}

Inicialmente, o regime militar reconhecia a morte de seus opositores políticos. A tortura permanecia no interior dos porões, ela mesma enclausurada e silenciada, mas os dirigentes da repressão davam-se ao trabalho de publicar notas, infames é verdade, mas que levavam a conhecimento a ocorrência das mortes. Para o ponto que se buscou defender aqui, não importavam todo o cinismo e a imaginação por trás das ditas notas oficiais e suas histórias fajutas sobre suicídios e tentativas de fuga; importava a morte como fato irreversível e definitivo, a colocar os mortos em lugar, dando-lhes o estatuto de não mais pertencerem a este mundo, e conferindo às famílias o direito de realizar o cortejo fúnebre de seus entes queridos.

Em contraposição, a lógica perversa do crime de desaparecimento forçado reside justamente na ambiguidade do estado daqueles que não estão vivos nem mortos. Ausentam-se do convívio do mundo comum, mas isso não significa que eles não mais existam. Em última análise, com o passar do tempo, cria-se a ficção jurídica de que estão mortos, com a suposta finalidade de estabilizar a situação e sanar a incerteza, o que só é possível porque o tempo demonstra a improbabilidade dos desaparecidos voltarem ou, a contrario sensu, a probabilidade de estarem mortos.

Objetivamente a incerteza deixa de existir, se é que um dia chegou a existir a não ser na forma de esperança, ela própria em geral subconsciente ou até inconsciente. Na maior parte das vezes, sabe-se que os desaparecidos foram mortos, aproximadamente quando, sabe-se também em que contexto. Mas o que está em jogo quando se debate a questão dos desaparecidos políticos, ficticiamente considerados mortos, é bem mais profundo do que esse raciocínio lógico, mas não rastreado nem publicizado. É que, para que algo tenha realidade, diria Hannah Arendt, é preciso que tenha aparência. Para que seja real, a coisa deve poder ser vista e ouvida por outros como por mim, é preciso que ela seja posta sob os holofotes do espaço público. Sem isso, o raciocínio e o convencimento de cada um, por mais racionais que sejam, não bastam.

A semântica nos mostra, sem maiores dificuldades, que mortos reais não são a mesma coisa que os desaparecidos nem tampouco que os mortos fictícios. É justamente esta ficção que não pode ser tolerada - há que se derrubá-la. O início do caminho das pedras foi indicado pela Corte Interamericana de Direitos Humanos: desmantelar esta ficção importa tornar 
reais as mortes, o que exige a investigação das circunstâncias em que ocorreram, o esclarecimento do paredeiro dos corpos, esforços para a localização dos restos mortais e, ao mesmo tempo, a assunção de responsabilidade pelo Estado.

Para além disso, a preocupação central deste trabalho foi demonstrar que, junto com a ficção dos desaparecidos políticos tidos por mortos, caem por terra as ficções da ditabranda institucionalizada e judicializada. Se a ditadura escancarada foi a que mais ocultou e se ocultou, é porque ela nega e contradiz todo o comedimento da repressão que um olhar puramente matemático sobre o regime militar poderia sugerir. A guerrilha do Araguaia se apresenta aqui como episódio simbólico porque foi a mostra extrema e radical da articulação entre política de extermínio, crimes de desaparecimento forçado e o sigilo oficial absoluto. Mas enquanto seus mortos persistirem envoltos no manto da ficção, por exclusão lógica, não é possível alçá-la, senão de forma precária e incompleta, à condição de capítulo efetivo da história política brasileira recente.

Para finalizar, mais como forma de apelo do que como conclusão, registra-se que o enfrentamento dos silêncios e das ficções criadas por nefastas razões de Estado do regime militar é o único caminho para se evitar que repitam e o único modo de se aproximar um pouco mais da hipérbole que é a justiça.

\section{REFERÊNCIAS BIBLIOGRÁFICAS}

ALVES, Maria Helena Moreira. Estado e Oposição no Brasil: 1964-1984. Bauru: EDUSC, 2005.

ARENDT, Hannah. Crises da República. São Paulo: Editora Perspectiva, 1999.

CASSESE, Antonio. International Criminal Law. New York: Oxford, 2008.

CIDH. Caso Gomes Lund. Sentença de 24 de Novembro de 2010, Serie C, n 219.

CIDH. Caso Vélázques Rodríguez. Sentencia de 4 de Julio de 1988. Serie C, n ${ }^{\circ} 4$.

CITRONI, Gabriella; SCOVAZZI, Tulio. The Struggle against enforced disappearance and the 2007 United Nations Convention. Leiden: Martinus Nijhoff, 2007.

COMISSÃO ESPECIAL SOBRE MORTOS E DESAPARECIDOS POLÍTICOS. Direito à Memória e à Verdade: Comissão Especial sobre Mortos e Desaparecidos Políticos. Brasília: Secretaria Especial dos Direitos Humanos, 2007.

DERRIDA, Jacques. Papier Machine. Paris: Galilée, 2001.

DWORKIN, Ronald. Law's Empire. Cambridge, Massachusetts: Harvard University Press, 1986.

FINUCANE, Brian. Enforced Disappearance as a crime under International Law: a neglected origin in the laws of war. Yale journal of international law. New Haven, no 35, 171-197.

FORÇAS GUERRILHEIRAS DO ARAGUAIA. Diário da Guerrilha do Araguaia. São Paulo: Editora Alfa-Omega, 1979.

GASPARI, Elio. A Ditadura Escancarada. São Paulo: Companhia das Letras, 2002. 
INTERNATIONAL MILITARY TRIBUNAL OF NUREMBERG. The Trial of German Major war Criminals - proceedings of the international military tribunal sitting at Nuremberg. Vol. 3. London: 1950.

LEMOS, Renato. Contrarrevolução e Ditadura no Brasil: elementos para uma periodização do processo político brasileiro pós-1964. Comunicação apresentada no VI Congrès du CEISAL (Conseil Européen de Recherche en Sciences Sociales sur l'Amérique Latine) Indépendances, Dépendances, Interdépendances, Toulouse, France, 30 de junho a 3 de julho de 2010.

MIRANDA, Nilmário; TIBÚRCIO, Carlos. Dos Filhos deste Solo: mortos e desaparecidos políticos durante a ditadura militar. São Paulo: Fundação Perseu Abramo, 1999.

PEREIRA, Anthony W. Ditadura e Repressão: o autoritarismo e o estado de direito no Brasil, no Chile e na Argentina. Tradução de Patrícia de Queiroz Carvalho Zimbres. São Paulo: Paz e Terra, 2010.

REGAZZONI, Simone. Al di là della Pulsione di Potere: Derrida e la decostruzione della sovranità. In: DERRIDA, Jacques. Incondizionalità o Sovranità. Trad. Simone Regazzoni. Milano: Mimesis, 2008.

SCHMITT, Carl. La Dictadura. Madrid: Revista de Occidente, 1968.

STUDART, Hugo. A Lei da Selva: estratégias, imaginário e discurso dos militares sobre a guerrilha do Araguaia. São Paulo: Geração Editorial, 2006.

WERLE, Gehard. Principles of International Criminal Law. The Hague: TMC Asser Press, 2005. 